\title{
Creating Shared Visions in Organizations - Taking an Organizational Learning and Knowledge Management Perspective
}

\author{
Alexander Kaiser \\ Vienna University of Economics \\ and Business \\ Austria \\ alexander.kaiser@wu.ac.at
}

\author{
Florian Fahrenbach \\ Vienna University of Economics \\ and Business \\ Austria \\ florian.fahrenbach@wu.ac.at
}

\author{
Hector A. Martinez \\ INCAE Business School \\ Costa Rica \\ hector.martinez@incae.edu
}

\begin{abstract}
This paper is based on the observation that literature on shared visions is either mainly dominated by top-down vision communication, which aims at followers taking over the vision of a leader, or accounts on shared visions are too narrow and too unspecific to be of much use for organizational practice. As a consequence, we currently lack an applicable process model that facilitates the creation of a shared organizational visions in a bottom-up manner. This paper aims at introducing and theoretically grounding such a process model. We find that the creation of a shared organizational vision can be seen as an instance of a knowledge creating and organizational learning process that transforms personal visions and personal organizational visions through a dialectic process towards a shared organizational vision. During this process, knowledge about needs, values, resources and desires is created and shared in the organization. In so doing, we summarize extant literature on developing shared visions and synthesize the literature into a process model which can be applied by academics and practitioners alike.
\end{abstract}

\section{Introduction}

Shared visions have been prevalent in the management literature since the $1980 \mathrm{~s}$. A shared vision can be defined as "awareness of employees to the organization's strategic objectives and future aspirations" [14] or as a "common mental model of the future state of a team or its tasks that provides the basis for action within the team" [32]. In the literature, shared visions have been seen as antecedents to the learning organization [38], the learning orientation of an organization $[5,40]$ and collective engagement in organizations [14].

However, much of the literature written on shared visions in organizations treats them as being developed by a leader and communicated in a top-down manner to followers $[6,7,14]$. Consequently, much less research has looked at how followers can contribute to the vision development process. This gap exists even though considerable work on motivation and job performance has identified the impact and benefits of employee autonomy in their work $[2,16,18,28]$ and meaningful work [3, 4, 41]. With some notable exceptions [20], there is even less literature on vision development in small groups (up to 50 people) from the perspective of organizational learning and knowledge management. These two theoretical perspectives are well suitable to describe the underlying dynamics of a vision development process and provide it with structure.

Therefore, our research question is: What could a process model look like to develop shared visions in organizations up to 50 people?

The purpose of this paper is to propose a processmodel that describes the bottom-up development of shared visions from a knowledge management and organizational learning perspective for organizations up to 50 people and illustrate the process-model with two case studies to demonstrate its practical utility. We chose organizations up to 50 people as a boundary condition as we experienced in field-work that the proposed vision development process does not work properly in larger organizations due to time restrictions and the unwillingness of participants to share personal experiences in larger groups.

The concept of shared vision has received considerable attention since the publication of Peter Senge's fifth discipline [38] within the field of organizational learning and the learning organization, however we still lack a coherent and structured process to co-create shared visions. This paper aims to fill this void and thus contributes to the core of the learning organization by outlining a structured process model how people in small organizations can develop a shared vision bottom-up and illustrate the approach with two case studies. Already in 2013 at HICSS-46 a model for knowledge-based vision development has been proposed [20]. This time, the focus is on the practical implementation, the detailed process model and the 
relation to state of the art approaches in knowledge creation and organizational learning.

The remainder of the paper is structured as follows. Section 2 presents the theoretical background on shared visions and related knowledge assets. Section 3 presents the process model to develop shared visions in organizations up to 50 people. Section 4 presents two case studies to illustrate how the process model can be applied in organizational practice. Section 5 theoretically grounds the process model in theory on konwledge creation and organizational learning. Section 6 presents limitations, outlines further research and concludes.

\section{Theoretical background}

\subsection{Shared visions}

Literature on shared vision is largely separated into a "top-down" and a "bottom-up" camp. While the topdown camp argues that a leader's vision is shared through communicating the vision top-down, the bottom-up camp [e.g. 21, 38, 43] argues a vision should be developed or created bottom-up through sharing several personal visions in a group or organization.

The "top-down camp" sees a shared vision as resembling the leaders personal vision which is communicated in specific ways to followers in a topdown manner. This approach aims at followers taking over the vision of the leaders. Within research and practice, the emphasis is on the proper way of communicating the vision to followers (e.g. through mental imagery, vivid descriptions and authentic emotions) $[6,7,42]$ with the goal of creating a shared cognition. Empirical research, especially on the properties of vision communication, has been conducted extensively $[6,7,14]$.

The "bottom-up camp" advocates behaviors that delegate "authority to employees, promoting their selfdirected and autonomous decision-making, coaching, sharing information, and asking for input" [39]. The bottom-up camp focuses on the communication between leaders and followers and letting go of control from the sphere of the leaders towards the sphere of the followers $[1,22,24]$. Here, the importance of the single individual for the organization is advocated and the top management supports the individual self-expression within the organizational frame. Contrary to communicating visions top-down, shared visions are build bottom-up and emerge from each personal vision. In other words, the organizational vision is an emergent property of each personal vision.

Also Senge [38] belonged to the "bottom-up camp" [e.g. 43] and described a shared vision as "a force in people's hearts" [38] that answers the question: "What do we want to create?" [38]. Senge [38] states that "shared visions derive their power from a common caring $[\ldots]$ and provide focus and energy for learning". Shared visions "emerge from personal visions" as "genuine caring about a shared vision is rooted in personal visions" [38]. He goes on stating that organizations which want to foster shared visions should "continually encourage members to develop their personal visions" [38], so that they do not have to sign up for someone's elses. In sum, Senge [38] defined a shared vision as "the capacity to hold a shared picture of the future we seek to create". Regarding the impact of shared visions, he states "when there is a genuine vision (as opposed to the all-too-familiar 'vision statement') people excel and learn, not because they are told to, but because they want to". Several authors took up the idea and conceptualized shared visions in more detail $[13,20]$. However, literature so far falls short in providing a detailed and applicable process-model that describes how to co-create shared visions based on the personal visions of all members in an organization.

\subsection{Knowledge assets in shared visions}

Looking into the extant literature on what motivates human behavior at work [e.g. 11, 12, 25, 26], we observe several high-level constructs that are relevant for creating personal visions and shared organizational visions. In order to keep complexity at a level that researchers and practitioners can handle, we limit ourselves to four high level constructs to create personal and shared organizational visions: needs, values, resources and desires. First, people have to satisfy their needs in order to thrive [11]. While there are many theories of needs $[10,17,27]$, a common factor is that people are seldom aware of them. In other words, people have to make them explicit [25]. Furthermore, "understanding the deepest common needs" [35] through dialectical methods such as provocative questions, listening and reflecting is usually seen as an important part of creating a shared sense of purpose. Second, cognitively representing human needs is a key function of values [37]. While needs are a property of the person (i.e. need for water) and are related to the avoidance of suffering, values remain when stripping away the human aspects of constructs (i.e. independence, security) [36]. Third, in order for people to satisfy their needs, they have to have certain resources, either personal in the form of strengths, competences, knowledge and skills or impersonal in the form of social networks or monetary resources [25]. Fourth, people have desires that provide a very specific direction for human behavior [15]. In other words, while needs can be seen as the force that set a person in motion (i.e. the motivate behavior), desires provide the direction (the specific way in which a person satisfies a need) of where a person wants to go in order to satisfy their needs [11]. 


\section{A process model for developing shared visions}

Based on the knowledge assets that are transformed when creating shared organizational visions, we present a comprehensive process model for its development in the following. To explain how a shared organizational vision emerges from the individuals in an organization, we introduce three different types of visions, namely the personal vision, the personal organizational vision and the shared organizational vision.

- First, the personal vision is defined as a holistic vision [38] of a single person. This personal vision includes all areas of life that are relevant for a specific person. It often includes the family, community, the organization and the world of the person that creates the vision. A concrete example of a personal vision can be found in case study 1 in the next section (Participant A).

- Second, the personal organizational vision is an image of how each individual organizational member envisions the organization in which he/she works in the future. In the personal organizational vision, a person defines how the organization helps to fulfill the personal vision. It can be seen as an intermediate artifact that crosses the individual and organizational sphere. Case study 1 provides an example of a personal organizational vision. The example shows that the personal organizational vision often consists of a comparable set of knowledge assets as the personal vision, but these knowledge assets are applied to a different and more specific environment, namely the organization. The personal organizational vision is shared in groups or (sub)-systems of the organization.

- Third, the shared organizational vision is defined as the vision of the entire organization, which is actionguiding for the future and provides essential orientation for strategy-making and decisions in the organization. Case 1 provides an example of an shared organizational vision that emerged from several personal visions and personal organizational visions.

It is important to note, that the personal vision strongly determines the personal organizational vision and the personal organizational vision strongly influences the organizational vision. In the context of shared vision development in organizations up to 50 people, the process of coming from a set of personal visions to a set of personal organizational visions to a shared organizational vision can be roughly described as follows:

First, each participant in the vision development process (in an ideal scenario all "relevant" members of an organization) prepares a personal vision. A personal vision is a narrative in written and explicated form (such as a short story), which describes the fulfilled future of person and guides the actions of a person. Second, each participant creates a personal organizational vision that contains $100 \%$ of all relevant aspects of the personal vision and transfers it to the organizational level (see example in case study 1). Each participant creates a personal organizational vision to define what the organization should look like in order to meaningfully contribute to the fulfilment of the personal vision. Third, all prepared personal organizational visions are shared with all participants in the vision development process. Together the participants develop a shared organizational vision. This shared organizational vision must contain the most important aspects of all personal organizational visions. However, to achieve a shared organizational vision, each individual personal organizational vision does not have to be $100 \%$ in line with the shared organizational vision. Experience from several projects we have already conducted shows, that an overlap of approximately $70 \%$ between the personal organizational vision and the shared organizational vision is considered sufficient to allow for the formation of a viable consensus within the group, as there is a negotiation potential of around $30 \%$ for each personal organizational vision. As the personal organizational vision aims to cover the relevant knowledge assets of the underlying personal vision in a comprehensive way, at least $70 \%$ of these relevant personal knowledge assets (values, needs, desires, strength, etc.) should emerge and thus be included in the shared organizational vision. The overall process looks like pointed out in Figure 1.

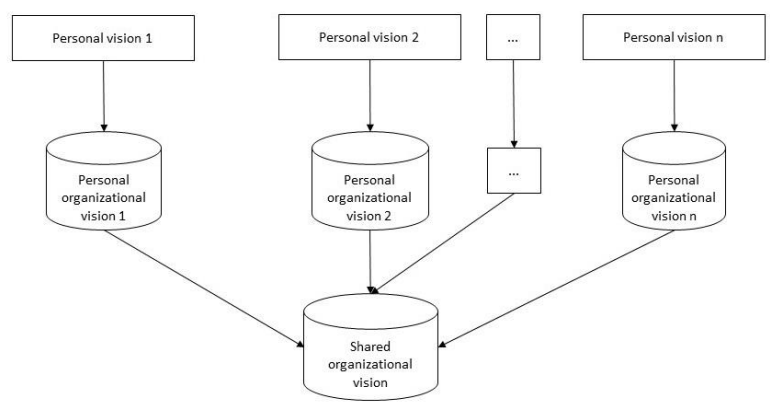

Figure 1: Overall process model

Figure 2 shows the development process from personal visions to personal organizational visions to shared organizational visions in more detail.

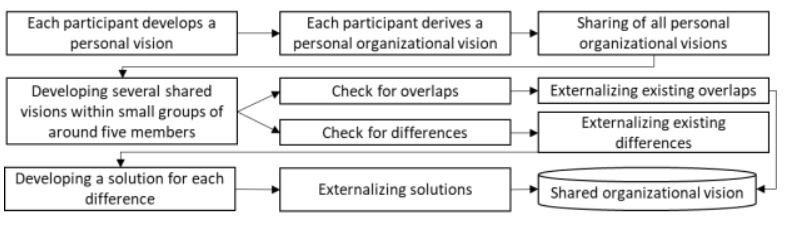

Figure 2: Detailed development process

In sum, the result of this process is not only a shared organizational vision that is developed but also the 
development process itself is shared (i.e. it hinges on the participants sharing of one's values, needs, desires and strengths in a process of explicating and sharing personal knowledge assets.

\section{Two Case studies}

We rely on two case studies to better illustrate the main ideas of our proposed shared development process for a shared organizational vision. We use the first case study to illustrate the difference between the three types of vision (personal vision, personal organizational vision and shared organizational vision) to describe the knowledge flow (knowledge exchange, transfer and sharing) towards the shared organizational vision. Although the second case study also follows the main aspects of our proposed process model for developing shared organizational visions, we have applied different tools and methods there. Therefore, we use case study 2 to illustrate the process itself.

\subsection{Case study - 1}

The first case study was conducted with the Corporate Internal Audit department, with about 40 internal auditors of an integrated international oil and gas company, headquartered in Vienna. The overarching goal of this project was to develop a shared vision for the whole internal audit department consisting of three national audit departments with around 40 members, which is compatible with the main orientation of the company. The vision development process lasted for about five months covering two workshops with all members of the department. In this case study we have applied the Vikobama method [20], which is based on systemic coaching and vocation-coaching [20, 21] approaches. Vikobama is a precise implementation of the proposed process model for developing shared visions into practical tools. Within the first workshop, the participants were accompanied to formulate their own personal vision along three action-guiding questions: What do I need for a fulfilling life and a fulfilling work? What do I want and what do I wish for my future? What are my resources, strengths and constraints? The following is an example of the personal vision of one participant (participant A):

- $\quad$ "I am a positive and inspirational contribution to my community. Kindness and compassion drive my actions toward others. My presence allows me and others to pursue their dreams and obtain them."

- "Things I really enjoy doing: Having a nice home and belongings; making others' lives easier or more pleasant; enjoying to be with my children \& friends."

- "What brings me happiness/joy: Friendship; a good discussion with good positive people."

- "Issues or causes I care deeply about: Remaining fit and healthy, keeping valuable friendships."
- "My most important values: Having integrity; being fit and healthy; having a nice home and belongings; leaving the world a better place; having fun; learning and improving myself; making others' lives easier or more pleasant; enjoying to be with my children \& friends.",

Based on the personal vision, each participant was asked to formulate a personal organizational vision. The personal organizational vision of participant A reads as follows:

- "We will be a customer-focused support organization that provides value-added audit and consulting services to assist in the achievement of the company's goals and performance objectives and in compliance with contract requirements."

- "We will be regarded as a valued resource by management, staff, and our audit clients. We will provide superior service and perform audits and studies in a spirit of partnership with objectivity, fairness, openness, and in accordance with the highest professional and ethical standards. We will provide our company with an institutional perspective on audit issues to assist in the seamless integration of operational, administrative, and technical resources."

- "We will work to deliver customer satisfaction. We believe in respecting our customers, listening to their requests, understanding their expectations, and delivering products and services, in a timely and cost-competitive manner that meet agreedupon standards."

- "We will promote teamwork, efficiency, innovation, workforce diversity, and the development of the individual by encouraging participation, mutual support, creativity, personal excellence, continuing education, and challenging standards of performance. "

- "We continually improve our auditing and consulting programs and strive toward technological and industry leadership. We will support the pursuit of professional advancement and the sharing of knowledge and experience with our peers. "

In the end, the members of the department formulated the following short overall vision together:

"Keep Momentum! Internal Audit is the critical reflection of our business activities. Today. And tomorrow. We are your constructive and credible dialogue partner for the value-driven development of the company, between the poles of risks and chances."

Based on this short vision a detailed vision has been formulated [20]. In the following we point out some parts of this vision, the full text can be found at https://bit.ly/2ZxLQe6 
"Integrity and keeping always the highest ethical standards are our underlying core values when performing our work. We act as an independent and objective function, provide fair and competent insight and take full accountability for our reports. Our critical reflection of our business activities is based on the Latin proverb 'audiatur et altera pars' ('hear the other side'). Active and empathic listening combined with a healthy dose of inquisitiveness is our proactive approach to ask good questions with the target to find room for improvement. We seek first to understand, then to be understood in order to give honest and accurate feedback. In order to fully understand, we take the time, pay the required attention and consider the context of the work presented and the outcomes that the person or group is working toward. [...] We act as one team across the three hubs making full use of our collective intellect. Our auditors are intrinsic motivated by having meaningful goals, sufficient autonomy and resources to develop their own mastery. [...] Internal audit is regarded as a talent pool for career-minded auditors to develop skilled and driven individuals into future leaders. In that sense, we are proud to be the eyes and ears of the Board".

This data aims to illustrate the knowledge flows from a personal vision to a personal organizational vision towards a shared organizational vision. The personal vision of participant $\mathrm{A}$ is quite detailed and holistic. In order to transform this personal vision into a personal organizational vision, it is necessary to grasp the essence (the most important features and characteristics) of the personal vision and apply this essence to the basic conditions of the organization. In a similar way, when all personal organizational visions have been shared, the essences of these visions are used to create the foundations of a shared organizational vision. Finally, a detailed shared organizational vision can be formulated which is based on these fundamentals. Figure 3 depicts the flow of knowledge using the data from "participant A".

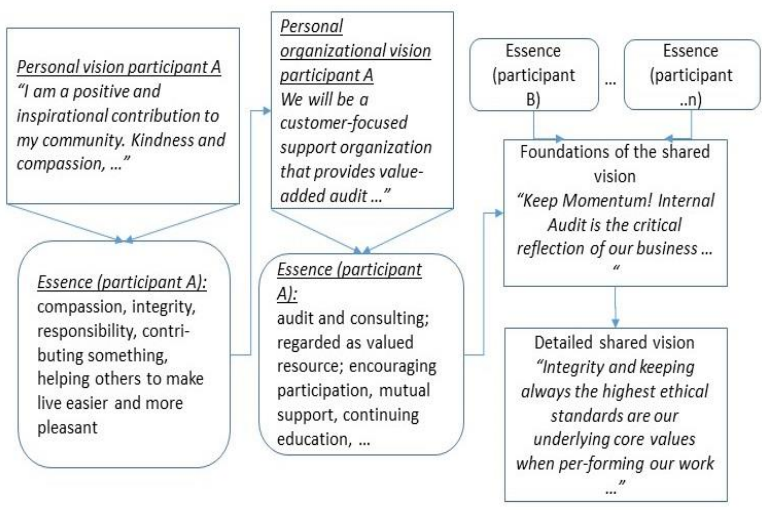

Figure 3: Depiction of participant A's knowledge flow

\subsection{Case study - 2}

The following is an account of an organizational development process at a recruiting department - made up of 19 individuals that are located in nine different countries in Latin America, more precisely at a business school in Central America. This case illustrates four aspects of the Shared Vision process model: (1) sharing of personal organizational visions, (2) developing shared visions in small groups, (3) identifying overlaps and gaps in visions, and (4) developing a shared organizational vision from existing overlaps.

The intervention - realized through a series of four online meetings in early 2020 — had two main objectives. First, to help department members to reengage with their work, and second, to help them to coordinate and collaborate on the recruiting numbers for the upcoming MBA recruiting season. The coordinators of the recruiting department had concerns about these two objectives as the Covid-19 pandemic had disrupted the established recruiting processes. Through the intervention, the department coordinators wanted to: (1) reinforce the important of a recruiter's role among the department's members; (2) facilitate group interaction to engage members of the department with each other and the business school's vision; (3) provide department members with an opportunity to express their concerns and opinions about how to move forward with the new structure; (4) identify opportunities in the structure, execution or the knowledge base of the members, which can be addressed by the coordinators; (5) help build better relationships amongst the department members, who as mentioned above, recruit from 9 different countries, yet need to coordinate and collaborate on different points in the recruiting process; (6) finally help a new coordinator transition into her new role in the department.

To realize these objectives, the organizational development process was structured using appreciative inquiry 4D's (i.e. discovery, dream, design, and destiny) as the coordinating model [8]. The first phase of the model (i.e. the discovery phase), looked to facilitate the expression and sharing of the implicit personal organizational visions of each individual member. The personal organizational vision of each department members was prompted by asking members to share one or more of their own personal recruiting stories that evoked pride in them. The appreciative inquiry process regularly prompts the expression of these types of "high-point" stories, because within those stories, examples of the organization at its best [8] are captured. When each member expresses their implicit personal organizational vision in these stories, the stories create a type of shared inventory of what the organization is able to accomplish. Eventually, it is with these examples that the shared organizational vision is in part constructed. 
The personal organizational visions were shared in groups of five. After sharing these stories in the groups, the groups presented a high level report (i.e. the essence) to the entire department. After those presentations, the 5-person groups were asked to express the function and impact of the recruiter for both the school and the prospective students. This question works as a bridge from the Discovery phase towards the next phase (i.e. Dream phase) of appreciative inquiry. The prompt looks to elevate the personal organizational visions into a shared, constructed metaphor. The metaphor helps the members to express a clearer vision of the department and the organization. The initial expression of the metaphor expressed by members provided an image of a group of miners, sifting through ruble and dirt in the depths of the earth to find unfinished gems that would be polished in the surface. This metaphor captured numerous positive values, such as humility, hard-work, and sacrifice, and also provided an image of the recruiters' separation from the result of their work. In other words, participants did not have enough data (i.e. post recruitment), to express a more holistic metaphor. As result of this expression, the recruiters were given the opportunity to interview graduates from the school that worked in the recruiting department. Each group of 5 had two graduated, and the others in the group had the opportunity to interview around two questions: 1 . What has been the impact of your MBA in your life? and 2 . What was the role of your recruiter in making your decision to enter the MBA?

These two questions generated a more integral and precise metaphor for the recruiters: the function of the recruiters was to be a motivating coach for prospects students, providing the important first contact in the transition between life before the MBA and an education that transformed how prospective students saw the world, how they interacted with others, and then gained access to jobs that would allow them to have a more inspiring future. The expression of how graduates saw their lives after the MBA, helped recruiters to see the opportunities provided for prospects more clearly which in turn had an impact on knowledge and the possibility to improve their economic situation. Furthermore, graduates remembered and expressed substantial appreciation for the role that the recruiters played on their MBA journey. With this shared constructed vision, the members of the recruiting department were able to link their roles to the mission of the business school, generating a shared organizational vision.

\subsection{Findings from the two case studies}

What can be seen well in both case studies is the interplay between abstraction and concretization. Abstraction is necessary and helpful to make the essence of a vision explicit to the members of the groups, and thus communicable and addressable. Once expressed and shared, the vision becomes a group construct that can be internalized and operationalized by each individual member. Furthermore, the steps of abstraction help to facilitate an identification of the overlaps between the diverse personal visions, and thus develop the essence of a shared organizational vision that connects to all personal visions and personal organizational visions. On the other hand, the phases of concretization are helpful to involve emotion and thus also motivation in the vision development process. This is necessary to enable the implementation of the shared organizational vision into reality and practice. Similar to the underlying idea of the SECI spiral [29] it could be argued that it is this interplay of abstraction and concretization that enables the creation of new knowledge, which forms the basis for a viable shared organizational vision.

\section{A knowledge management and organizational learning perspective on developing shared vision}

This section will start by outlining the flow of knowledge and knowledge assets within this proposed process of developing a shared organizational vision. Subsequently, a perspective of knowledge creation and organizational learning conceptually illuminates these processes.

\subsection{Knowledge flows}

First, preparing a personal vision story requires knowledge of all relevant aspects that are important for a person's motivation and thus flourishing life. According to Kelly [23] this includes knowledge about one's needs [35] by answering the question of what I need to live a fulfilled life, as well as the knowledge about deep desires and wishes by answering the question of what I really wish and desire for my future. Being able to write a personal vision also requires knowledge of important personal values [36] that guide action and finally knowledge about personal resources, strengths and talents. All these knowledge assets have to be made explicit in order to be able to formulate a personal vision story.

Transferring all these knowledge assets to an organizational level and preparing a personal organizational vision not only strengthens the competence of systems thinking [38] but also creates knowledge about which different (sub)-systems are relevant for each person and how these (sub)-systems can interact with each other to enable a fulfilled life for each person.

Sharing all personal organizational visions with each other promotes the exchange of already existing knowledge within the organization. As the personal organizational vision contains the different knowledge assets underlying personal vision, this step also enables the sharing of very essential core knowledge (i.e. 
knowledge assets) of each participant. It can be argued that this step enables the conversion of implicit organizational knowledge to explicit organizational knowledge.

Finally, the creation of a shared organizational vision based on the numerous personal organizational visions creates twofold knowledge flows. New knowledge is created, as the contents of the numerous personal organizational visions are of course partly different and contradictory. This is in line with [31] who state that knowledge creation can be seen as a dialectical process, in which various contradictions are synthesized through dynamic interactions among individuals, the organization, and the environment. Furthermore, directly useful knowledge about the priority of tasks in the near future and the goals that have to be achieved is created in these knowledge flows.

\subsection{A knowledge creation perspective on developing shared vision}

The knowledge flow within the shared development process of a shared vision can be deducted from the SECI model [29]. Based on the assumption that knowledge is noted to contain a tacit dimension and an explicit dimension [34], the SECI model defines four ways that knowledge assets can be combined and converted, showing how knowledge is shared and created in the organization [33]. These four ways are socialization, externalization, combination and internalization. Figure 4 shows all four phases of the SECI model applied to the development process of shared organizational visions at a glance.

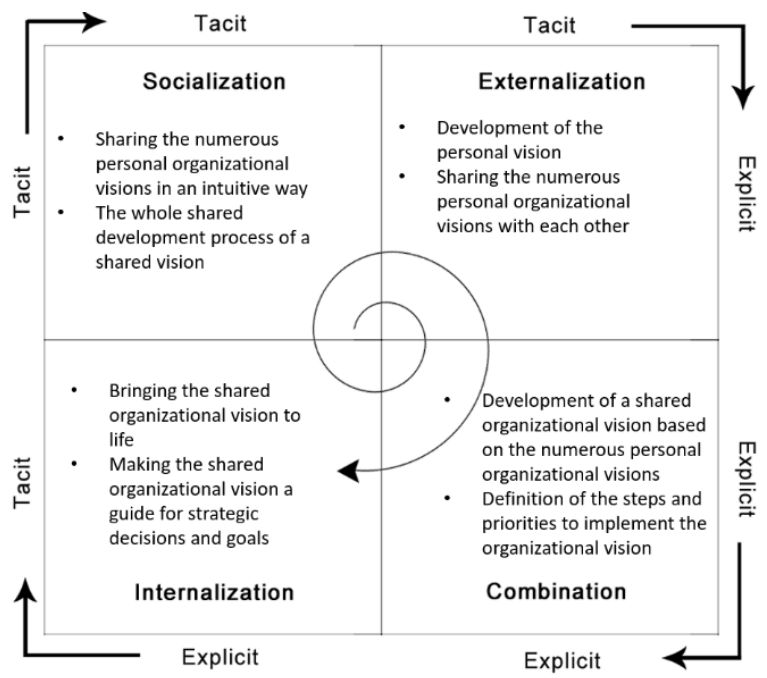

Figure 4: A knowledge creation perspective on shared organizational visions.

During the socialization phase, individuals acquire tacit knowledge through practice and informal interactions. Socialization is a process of sharing experiences and thereby creating tacit knowledge and it occurs when people spend time together [33]. Given this background, it can be argued that the whole process of developing a shared organizational vision covers the socialization phase of the SECI model. In particular, the part of the vision development process in which the numerous personal organizational visions are shared in an intuitive way is part of the socialization phase of the SECI model.

Externalisation covers the expression of tacit knowledge and its translation into forms that can be communicated to others and understood by others. Nonaka and Toyama [31] argue that in this phase, individuals externalize and dialectically synthesize the contradictions between their tacit knowledge and environment, or contradictions in the tacit knowledge between individuals. In our model, this takes place during the phase when creating personal visions, and in the phase of sharing the personal organizational visions with each other.

Combination involves the conversion of explicit knowledge into more complex sets of new explicit knowledge. Externalized tacit knowledge can be combined and presented in more explicit form, and verified with complementary knowledge within and beyond the firms' boundaries. Novel combinations of explicit knowledge can produce new knowledge [33]. This takes place while developing a shared organizational vision based on the numerous personal organizational visions and during the definition of the steps and priorities to implement the vision.

Internalization of newly created knowledge is the conversion of explicit knowledge into the organization's tacit knowledge. People internalize new knowledge through training, learning-by-doing or reflective practice and social interaction. The internalization phase describes how internalized explicit knowledge becomes a base for routines and individually held tacit knowledge [33]. In our proposed approach, this takes place by bringing the shared organizational vision to life and making it a guide for strategic decisions and goals.

In Nonaka and Takeuchi [29] and in a somewhat modified form recently in Nonaka and Takeuchi [30], multiple dimensions of the SECI spiral are introduced. With this model, the knowledge flows of the development process of a shared organizational vision can be well described on both the epistemological and ontological dimensions. Along the ontological dimension, we first have the individual level on which a complete SECI process takes place within the preparation of the personal vision and subsequently the preparation of the personal organizational visions. Next comes the group level, which is used to share the developed of a personal organizational visions. Here, different subgroups of the organization successively create their shared vision. This is followed by the organizational level, when a shared organizational vision has been completed and is supported by all members. Finally, the inter-organizational level takes place. By communicating the shared organizational vision, other organizations get a clear understanding of 
what the organization stands for. Figure 5 shows the epistemological and ontological dimensions within the development process for shared organizational visions.

The four knowledge assets (knowledge about needs, knowledge about desires and deep wishes, knowledge about values and knowledge about resources and strengths) we have introduced before, build up a knowledge chain [19] as they connect each ontological level with each other. These knowledge assets have to be externalized on the individual level in order to be able to formulate a personal vision. The group level helps to externalize the personal organizational vision of each member. However, also at the group level, members of each sub-group of the organization transform these four knowledge assets to create a shared vision of the group. At the organization level, these four knowledge assets of each subgroup enable the development of a shared organizational vision.

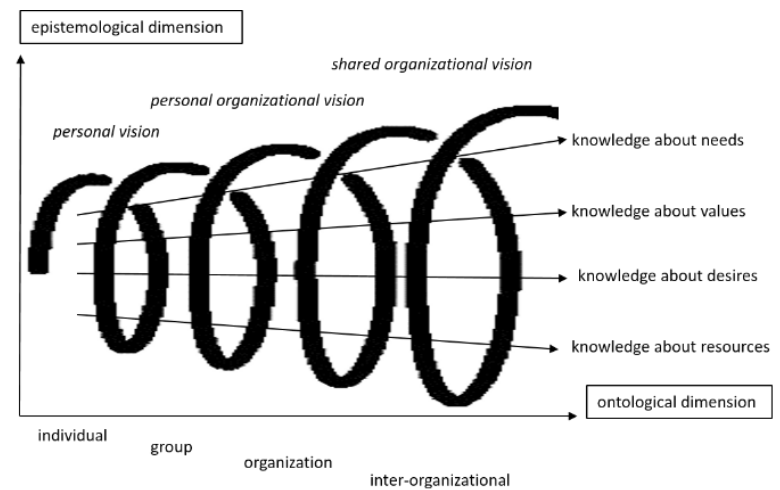

Figure 5: Epistemological and ontological dimensions when creating shared organizational visions

Finally, at the inter-organizational level, the four knowledge assets can be identified within the shared organizational vision and thus provide a valuable decision-making support for future cooperation. Therefore, there exists a continuity and traceability along these four knowledge assets across all ontological levels and also a mutual dependency and derivability from one ontological level to the next.

\subsection{Shared vision development and organizational learning}

From an organizational learning perspective, the proposed development process for a shared organizational vision can be deducted from the 4I Model of Organization Learning [9]. This framework contains four related processes (intuiting, interpreting, integrating, and institutionalizing) that occur over three levels (individual, group and organization). The three learning levels define the structure and processes through which organizational learning takes place. Characteristic for the 4I model are the related feedforward and feed-back processes. In short, "feedforward relates to exploration. It is the transference of learning from individuals and groups through to the learning that becomes embedded or institutionalized in the form of systems, structures, strategies, and procedures. Feedback relates to exploitation and to the way in which institutionalized learning affects individuals and groups" [9].

The 4I model builds up on the assumption that organizational learning is a dynamic process, not only over time and across levels, but also in creating a tension between assimilating new learning (feed-forward) and exploiting or using what has already been learned (feedback). Feed-forward processes, represent the flow of new ideas and actions from the individual to the group to the organization levels, while what has already been learned feeds back from the organization to group and individual levels, affecting how people act and think [9].

Our proposed development process of a shared organizational vision can be deducted from the main aspects of the 4I model. First, we observe the three onotological dimensions and the interplay between these levels along the whole development process as described above. Second, we observe the tension between feed-forward and feedback processes. The feed-forward process from the individual level (personal vision) and the group level (personal organizational vision) strongly effects the organizational level (shared organizational vision). At the same time, the feedback process from the organizational level and the group level back to the personal level not only helps to develop and shape the shared organizational vision, but also contributes to the fulfillment of the personal vision by externalizing concrete implementation possibilities of the personal vision in the organization.

From the perspective of organizational learning, our approach for the development of shared organizational visions can be seen as an organizational learning process along three different ontological dimensions (personal group - organization) and four epistemological dimensions (knowledge about needs, knowledge about values, knowledge about desires and knowledge about resources).

\section{Contributions, limitations and further research}

With this research endeavor, we contribute to theory and practice in the following way: Theoretically, we show that the development process of shared organizational visions can be seen as an instance of a knowledge creating and organizational learning process. Furthermore, we extend theory on shared visions towards four kind of knowledge assets: knowledge about needs, knowledge about values, knowledge about resources and knowledge about desires that are transformed (knowledge flow) when creating shared organizational visions. Furthermore, we show how shared organizational visions emerge from personal visions and personal organizational visions in a 
dialectic process that is facilitated by groups. In so doing, we contribute a bottom-up process model that takes into account the personal visions and personal organizational visions of all people involved and thus present an alternative to the "top-down camp" way how visions are shared in organizations. Practically, we contribute a comprehensive process to develop shared visions for organizations up to 50 people. However, this research approach is not without limitations.

Clearly, one limitation is the size of the organization in which the process model can be applied. If an organization is too large (i.e. more than 50 people) participants often feel uncomfortable in sharing the personal organizational visions. One way to mitigate this shortcoming is to present the personal organizational visions in small groups as described above. A second limitation is the case study approach. The evidence presented here is based on this evidence and the findings may be strengthed in further surveybased and longitudinal research. Also, further research may look into how the process of creating shared organizational visions may be supported by digital technologies to increase the size of participants the method can handle.

\section{References}

[1] Amundsen, S. and Ø.L. Martinsen, "Empowering leadership: Construct clarification, conceptualization, and validation of a new scale", The Leadership Quarterly, 25(3), 2014, pp. 487-511.

[2] Barrick, M.R. and M.K. Mount, "Autonomy as a moderator of the relationships between the Big Five personality dimensions and job performance", Journal of Applied Psychology, 78(1), 1993, pp. 111-118.

[3] Both-Nwabuwe, J.M.C., M.T.M. Dijkstra, and B. Beersma, "Sweeping the Floor or Putting a Man on the Moon: How to Define and Measure Meaningful Work", Frontiers in psychology, 8, 2017, p. 1658.

[4] Bunderson, J.S. and J.A. Thompson, "The Call of the Wild: Zookeepers, Callings, and the Double-edged Sword of Deeply Meaningful Work", Administrative Science Quarterly, 54(1), 2009, pp. 32-57.

[5] Calantone, R.J., S.T. Cavusgil, and Y. Zhao, "Learning orientation, firm innovation capability, and firm performance", Industrial Marketing Management, 31(6), 2002, pp. 515-524.

[6] Carton, A.M. and B.J. Lucas, "How can leaders overcome the blurry vision bias? Identifying an antidote to the paradox of vision communication", Academy of Management Journal, 61(6), 2018, pp. 2106-2129.

[7] Carton, A.M., C. Murphy, and J.R. Clark, "A (blurry) vision of the future: How leader rhetoric about ultimate goals influences performance", Academy of Management Journal, 57(6), 2014, pp. 1544-1570.
[8] Cooperrider, D. and S. Srivastva, "The Gift of New Eyes: Personal Reflections after 30 Years of Appreciative Inquiry in Organizational Life", in Research in Organizational Change and Development, A.B. (Rami) Shani and D.A. Noumair, Editors. 2017. Emerald Publishing Limited.

[9] Crossan, M., H.W. Lane, and R.E. White, "An organizational learning framework: from intuition to institution”, Academy of Management Review, 24(3), 1999, pp. 522-537.

[10] Deci, E.L. and R.M. Ryan, "The "What" and "Why" of Goal Pursuits: Human Needs and the Self-Determination of Behavior", Psychological Inquiry, 11(4), 2000, pp. 227-268.

[11] Dweck, C.S., "From needs to goals and representations: Foundations for a unified theory of motivation, personality, and development", Psychological review, 124(6), 2017, pp. 689-719.

[12] Eccles, J.S. and A. Wigfield, "Motivational beliefs, values, and goals", Annual review of psychology, 53, 2002, pp. 109-132.

[13] Eigeles, D., "Facilitating shared vision in the organization", Journal of European Industrial Training, 27(5), 2003, pp. 208-219.

[14] Eldor, L., "How Collective Engagement Creates Competitive Advantage for Organizations: A Business-Level Model of Shared Vision, Competitive Intensity, and Service Performance", Journal of Management Studies, 2019.

[15] Frankfurt, H.G., "Necessity and Desire", Philosophy and Phenomenological Research, 45(1), 1984, p. 1.

[16] Fuller, J.B., K. Hester, and S.S. Cox, "Proactive Personality and Job Performance: Exploring Job Autonomy as a Moderator", Journal of Managerial Issues, 22(1), 2010, pp. 35-51.

[17] Gasper, D., "Conceptualising human needs and wellbeing”, in Wellbeing in Developing Countries, I. Gough and J. MacGregor, Editors. 2007. Cambridge University Press: Cambridge.

[18] Hackman, J.R. and G.R. Oldham, Work redesign, Addison-Wesley, Reading MA, 1980.

[19] Holsapple, C.W. and M. Singh, "The knowledge chain model: activities for competitiveness", Expert Systems with Applications, 20(1), 2001, pp. 77-98.

[20] Anonymous, Details omitted for double-blind reviewing. in Proceedings of the 46th Hawaii International Conference on System Sciences, 2017.

[21] Kaiser, A. and B. Fordinal, "Creating a ba for generating self-transcending knowledge", Journal of Knowledge Management, 14(6), 2010, pp. 928-942.

[22] Kearney, E., M. Shemla, D. van Knippenberg, and F.A. Scholz, "A paradox perspective on the interactive effects of 
visionary and empowering leadership", Organizational Behavior and Human Decision Processes, 2019.

[23] Kelly, M., The rhythm of life: Living every day with passion and purpose. Simon \& Schuster, London, 2005.

[24] Kim, M., T.A. Beehr, and M.S. Prewett, "Employee Responses to Empowering Leadership: A Meta-Analysis", Journal of Leadership \& Organizational Studies, 25(3), 2018, pp. 257-276.

[25] Latham, G.P. and C.C. Pinder, "Work motivation theory and research at the dawn of the twenty-first century", Annual review of psychology, 56, 2005, pp. 485-516.

[26] Locke, E.A. and G.P. Latham, "What Should We Do about Motivation Theory? Six Recommendations for the Twenty-First Century", Academy of Management Review, 29(3), 2004, pp. 388-403.

[27] Max-Neef, M., "Development and human needs", in Development and human needs, P. Ekins and M. Max-Neef, Editors.

[28] Morgeson, F.P., K. Delaney-Klinger, and M.A. Hemingway, "The importance of job autonomy, cognitive ability, and job-related skill for predicting role breadth and job performance", The Journal of applied psychology, 90(2), 2005, pp. 399-406.

[29] Nonaka, I. and H. Takeuchi, The knowledge-creating company: How Japanese companies create the dynamics of innovation, Oxford Univ. Press, New York NY u.a., 1995.

[30] Nonaka, I. and H. Takeuchi, The wise company: How companies create continuous innovation, Oxford University Press, New York NY, 2020.

[31] Nonaka, I. and R. Toyama, "The knowledge-creating theory revisited: knowledge creation as a synthesizing process", Knowledge Management Research \& Practice, 1(1), 2003, pp. 2-10.

[32] Pearce, C.L. and M.D. Ensley, "A reciprocal and longitudinal investigation of the innovation process: the central role of shared vision in product and process innovation teams(PPITs)", Journal of Organizational Behavior, 25(2), 2004, pp. 259-278.

[33] Peltokorpi, V., I. Nonaka, and M. Kodama, "NTT DoCoMo's Launch of I-Mode in the Japanese Mobile Phone Market: A Knowledge Creation Perspective", Journal of Management Studies, 44(1), 2007, pp. 50-72.

[34] Polanyi, M., The Tacit Dimension, University Of Chicago Press, Chicago, 1966.

[35] Quinn, R.E. and A.V. Thakor, "Creating a purpose-driven organization”, Harvard Business Review, 96(4), 2018, pp. 7885 .

[36] Schwartz, S.H., "Are There Universal Aspects in the Structure and Contents of Human Values?", Journal of Social Issues, 50(4), 1994, pp. 19-45.
[37] Schwartz, S.H., "Functional theories of human values: Comment on Gouveia, Milfont, and Guerra (2014)", Personality and Individual Differences, 68, 2014, pp. 247249.

[38] Senge, P.M., The fifth discipline: The art and practice of the learning organization, Currency Doubleday, NY, 1990.

[39] Sharma, P.N. and B.L. Kirkman, "Leveraging Leaders", Group \& Organization Management, 40(2), 2015, pp. 193237.

[40] Sinkula, J.M., W.E. Baker, and T. Noordewier, "A framework for market-based organizational learning: Linking values, knowledge, and behavior", Journal of the Academy of Marketing Science, 25(4), 1997, p. 305.

[41] Steger, M.F., B.J. Dik, and R.D. Duffy, "Measuring Meaningful Work", Journal of Career Assessment, 20(3), 2012, pp. 322-337.

[42] Venus, M., D. Stam, and D. van Knippenberg, "Leader emotion as a catalyst of effective leader communication of visions, value-laden messages, and goals", Organizational Behavior and Human Decision Processes, 122(1), 2013, pp. 53-68.

[43] Wang, C.L. and M. Rafiq, "Organizational diversity and shared vision", European Journal of Innovation Management, 12(1), 2009, pp. 86-101. 